Roseana Mara Aredes Priuli ${ }^{1}$

M aria Silvia de M oraes ${ }^{1}$

\title{
Adolescentes em conflito com a lei
}

\author{
Adolescents in conflict with the law
}

1 Departamento de Epidemiologia e Saúde Coletiva, Faculdade de M edicina de São José do Rio Preto. Av. Brigadeiro Faria Lima 5416, Vila São Pedro. 15090-000 São José do Rio Preto SP. rosianap@terra.com.br
Abstract This study is focused on teenagers who behave violently and who are also victims of violence. The data was collected from records of adolescent inmates in São J osé do Rio Preto. The variables selected were: place of residence, age, education level, type of offense, drugs use, family income, parent education levels, jobs. The findings disclose a social and demographic profile for teenagers around seventeen years old with only elementary education. Themost common offence was robbery; followed by theft, homicide, drug dealing, and robbery leading to death. M ost of these teenagers smoked tobacco and marijuana, drank alcohol ic beverages and took crack. The data indicate a context defined by precarious living conditions wherefamily members havelow incomes and poor job skills, together with alcohol abuse. As a result, they help turn teenagers into victims of society. The mother - who typically supports the household - is the strongest presence during the incarceration period, serving as a mediator between the adolescent in conflict with the law, the courts and the community. In view of thehigh costs of interpersonal violence, it is necessary to develop and implement a municipal strategy for children and adolescents in São José do Rio Preto. Key words Violence, Adolescence, Government policies
Resumo 0 estudo focou 0 adolescente autor $\mathrm{e}$ vítima da violência, fenômeno crescente no Brasil. Dados col etados dos prontuários dos internos de São José do Rio Preto e seleção das variáveis: local demoradia, idade, escolaridade, tipo elocal das infrações, uso de drogas e ocupação, composição familiar, renda, escolaridade etrabalho dos pais. Os resultados revelaram perfil sociodemográfico, infracional e relacional de parte significativa com 17 anos, ensino fundamental incompleto, evadido da escola, sem trabal ho e resi dente na região norte, demenor poder soci oeconômico. A infração de maior percentual foi roubo, seguida de furto, tentativa de homicídio, homicídio, roubo qualificado, tráfico de drogas e roubo com morte, nos bairros da região norte. A maioria usava tabaco, maconha, álcool, crack; a minoria, cocaína, thinner e cola. Detectou-se realidade precária de familiares com baixo nível derenda, escolaridade, profissão eabuso deálcool, contribuindo para transformar os adolescentes em vítimas. A maioria das mães, provedora do lar, principal figura na internação e mediadora entre 0 adolescente, o poder judiciário e a comunidade. Considerando o elevado custo da violência interpessoal, concluímos, nesse estudo, a necessidade de políticas públicas para crianças e adolescentes na cidade de São José do Rio Preto. Pal avras-chave Violência, Adolescência, Políticas públicas 
Introdução

Nas duas últimas décadas do século XX, nas grandes cidades do mundo e em al guns países, como é o caso do Brasil, os dados epidemiológicos têm mostrado crescimento da morbidade e da mortalidade por causas externas.

Estimativas da Organização M undial de Saúde (OMS) para o ano de 2000 destacam que morreram cerca de 1,6 milhões de pessoas no mundo inteiro como resultado da violência ${ }^{1}$ ): $25 \%$ dessa mortalidade foram por acidentes de transporte, $16 \%$ por suicídio, $10 \%$ por violência interpessoal, $9 \%$ por afogamento, dentre outras².

De acordo com os dados do Relatório Mundial sobre Violência e Saúde ${ }^{1}$, constata-se que a taxa dehomicídios no Brasil foi de 23 por 100.000 habitantes, sendo que a da Colômbia foi de 61,6 por 100.000 habitantes. Já na região africana, como um todo, a taxa estimada para o ano de 2000 foi de 22,2 por 100.000 habitantes. Enquanto isso, se observam para alguns países europeus taxas comparativamente muito baixas, como da Dinamarca $(1,1)$; França $(0,7)$; Alemanha $(0,9)$; Grécia (1,2); Portugal $(1,1)$; Reino Unido $(0,8)$; Espanha $(0,8)$; dentre outros. As maiores taxas encontradas na Europa foram da Albânia (21) e da Federação Russa $(21,6)$.

Nos Estados Unidos da América, estima-se que a violência interpessoal, que inclui a violência entre membros da família, entre casais, a violência juvenil e entre pessoas estranhas, é de al to custo, chegando a um patamar de 3,3\% do Produto Interno Bruto do país. 0 fenômeno afeta principalmente países de menor poder aquisitivo, sendo que o efeito econômico dessa violência é mais severo em países pobres onde, entretanto, são escassos os estudos sobre esse assunto ${ }^{3,4}$.

Ainda com relação à dimensão econômica da violência interpessoal, chegou-se à conclusão de que os gastos ocorridos na prevenção da violência são menores do que os gastos para repará-la. Intervenções que tinham como focos agressões juvenis resultaram em benefícios econômicos trinta vezes maiores que os gastos para reparar esse tipo de violência?.

No panorama brasileiro, o aumento da mortalidadepor causas violentas vem setornando um fenômeno de alta relevância, pois no início da década de 80 ocupava o quarto lugar no perfil das principais causas de óbito, passando para o segundo lugar, a partir de 1989, perdendo apenas para as doenças do aparelho circulatório. Tratase, portanto, de um grave problema de saúde pública, fazendo com que a epidemia demortes vio- lentas na população jovem das grandes cidades seja uma das pautas da nova agenda da saúde pública, com sinais de evolução desfavorável e remetendo para um cenário futuro inquietante $e^{5,6,7,8}$.

Se, até meados da década de 1990, o crescimento da violência parecia estar restrito às grandes capitais da região sudeste do Brasil, hoje as taxas estão crescendo em capitais médias e mesmo pequenas. A região sudeste, mais rica e mais desigual, tem as taxas mais insistentemente altas. Este fato mostra que não se pode atribuir à pobreza extrema da região o aumento das taxas de homicídios ${ }^{9,10}$.

Estudos têm observado que as mortes por causas externas, muitas vezes resultantes de homicídio, têm como alvo preferencial adolescentes e jovens adultos, de 15 a 24 anos, masculinos, residentes em áreas periféricas ou menos favorecidas das grandes metrópoles urbanas e, portanto, carentes em termos socioeconômicos: em geral, possuem baixa escolaridade e preferencialmente são negros ou descendentes dessa etnia. É esse grupo de causas externas que explica, respectivamente, $46,5 \%$ das mortes na faixa de 05 a 14 anos e 64,4\% das mortes dos jovens de 15 a 29 anos, sendo nesses segmentos etários a primeira causa de morte ${ }^{11,12}$

A grande preocupação ante esse cenário de mudanças é a evidência de que grupos de jovens, sobretudo do sexo masculino, estão cada vez mais atingidos como vítimas e autores ${ }^{13,7,14}$.

Um estudo de 1999 com 5.425 jovens infratores entre 12 e 17 anos, na cidade de São Paulo, no período de 1988 a 1991, resultou que o envolvimento de jovens com o crime violento seguiu o mesmo padrão observado na população geral . Para um segundo estágio da pesquisa, com 3.893 jovens infratores, no período de 1993 a 1996, re sultou uma mudança no comportamento padrão desses jovens, com o surgimento do crime organizado e a formação de gangues. Quando o padrão de crime na população como um todo foi comparado com o correspondente no caso da delinqüênciajuvenil, verificou-seum aumento da violência entre os jovens ${ }^{14}$.

Também sob o enfoque do adolescente autor de atos infracionais, um estudo no município de Ribeirão Preto, São Paulo, cidade de médio porte do interior paulista, no período entre 1974 e 1996, revel ou um grande aumento de delitos cometidos por adolescentes. Além disso, o homicídio foi a infração que mais apresentou crescimento, aumentando quarenta vezes no período estudado. Em seguida, apareceu o tráfico de entorpecentes, que aumentou 23,75 vezes e a terceira 
infração quemais cresceu foi portede arma ( 18,8 vezes) ${ }^{15}$.

Ainda, dados fornecidos pela Fundação Estadual do Bem-Estar do M enor (Febem/SP) em 02/ 12/2003 para o período de janeiro/2003 a outubro/2003 revelaram um incremento de $21,7 \%$ no número de adolescentes infratores internos naquela instituição ${ }^{16}$.

Assim sendo, estudos mostram cada vez mais o envolvimento dejovens brasileiros com o mundo do crime; entretanto, pouco se sabe sobre esses jovens e o sistema judicial empregado para as crianças e adolescentes, em especial a competência da lei e das medidas oficiais adotadas para conter o crime entre esta população. N esse sentido, faz-se necessário pesquisar mais a realidade brasileira no que diz respeito à questão do adolescente em conflito com a lei, com o propósito de subsidiar as ações do judiciário, quando da aplicação das leis, como também as instituições que administram as medidas judiciais designadas aos jovens, representadas pela Fundação Estadual do Bem-Estar do M enor.

A partir do exposto, o presente trabalho objetiva levantar o perfil sociodemográfico, infracional e relacional de adolescentes em conflito com a lei do município de São José do Rio Preto no ano de 2003.

\section{Metodologia}

A população estudada consistiu de adolescentes do sexo masculino, residentes na cidade de São José do Rio Preto, entre 14 e 18 anos de idade completos, os quais cumpriam a medida socioeducativa de internação na Fundação Estadual do Bem-Estar do Menor (FEBEM/SP) no ano de 2003, totalizando 48 adolescentes.

A instituição FEBEM/SP oferece assistência para aproximadamente 18.000 crianças e adolescentes em todo o Estado de São Paulo, inseridos em programas socioeducativos específicos, como o de privação de liberdade e de liberdade assi stida, dependendo do grau infracional e da idade ${ }^{17}$.

Do panorama demográfico, segundo dados do Instituto Brasileiro deGeografia eEstatística ${ }^{18}$, São José do Rio Preto possui uma população geral de 367.247 habitantes, caracterizando-se pólo regional, com influência direta em 96 municípios ${ }^{19}$.

O município possui uma Unidade de Internação da FEBEM denominada Grandes Lagos, que abriga adolescentes infratores resi dentes em São J osé do Rio Preto e cidades vizinhas.

A coleta dos dados do estudo foi realizada medianteconsulta aos prontuários dos adolescentes disponibilizados pela instituição, por intermédio deum protocolo, obedecendo a todosos preceitos éticos em pesquisa, segundo o parecer $n$ ㅇ. 153/2003 de aprovação do Comitê de Ética em Pesquisa da Faculdade de M edicina de São José do Rio Preto.

Coletados os dados, foi construída uma base de dados em DBase II.I e utilizando-se do programa EPI - INFO foram produzidas as tabulações das informações para a caracterização da população em razão das variáveis arroladas.

0 tratamento dos dados forneceu a freqüência dos eventos e respectivas porcentagens, não tendo sido produzidas análises estatísticas e níveis designificância daquel es em função da totalidade da população. Tratou-se de um censo em que não houveo propósito de testar hipóteses eextrapolar os resultados obtidos para outros grupos.

\section{Resultados}

De acordo com a caracterização dos adolescentes internos naFEBEM Grandes Lagos, uma parte significante estava na faixa etária de 17 anos $(35,4 \%)$ e $(64,5 \%)$ nasceram na cidade de São José do Rio Preto. Observou-se que $68,7 \%$ possuíam o ensino fundamental incompleto e $83,3 \%$ não freqüentavam a escola. U ma grande partedos jovens (72,9\%) não realizava trabalho remunerado por ocasião da apreensão.

Faceàs variáveis estudadas, nossos resultados de investigação revelaram que quanto à distribuição geográfica de local de moradia dos adolescentes internados na Unidade Grandes Lagos, $50,0 \%$ residiam em bairros local izados na região norte do município e 20,8\% nas suas imediações.

Os tipos de infrações cometidas pela população (Figura 1) foram categorizados equiparandose à classificação do Código Penal que prescreve: infrações contra o patrimônio (furto - Artigo no. 155; roubo - Artigo 157; roubo qualificado - Artigo 157, parágrafo 2ㅇ; roubo seguido de morteArtigo 157, parágrafo 3ㅇ; ; infrações contra as pessoas (tentativa de homicídio, homicídio - Artigo 121); infração de tráfico de entorpecentes (comercialização de substâncias entorpecentes - Artigo 12 da lei complementar n‥6368).

Salientamos que, para uma análise mais acurada, foram separados os tipos de infrações contra o patrimônio em função da maior ou menor gravidade do ato equiparado ao critério de tempo de reclusão determinado pelo Código Penal para as pessoas maiores de idade. 


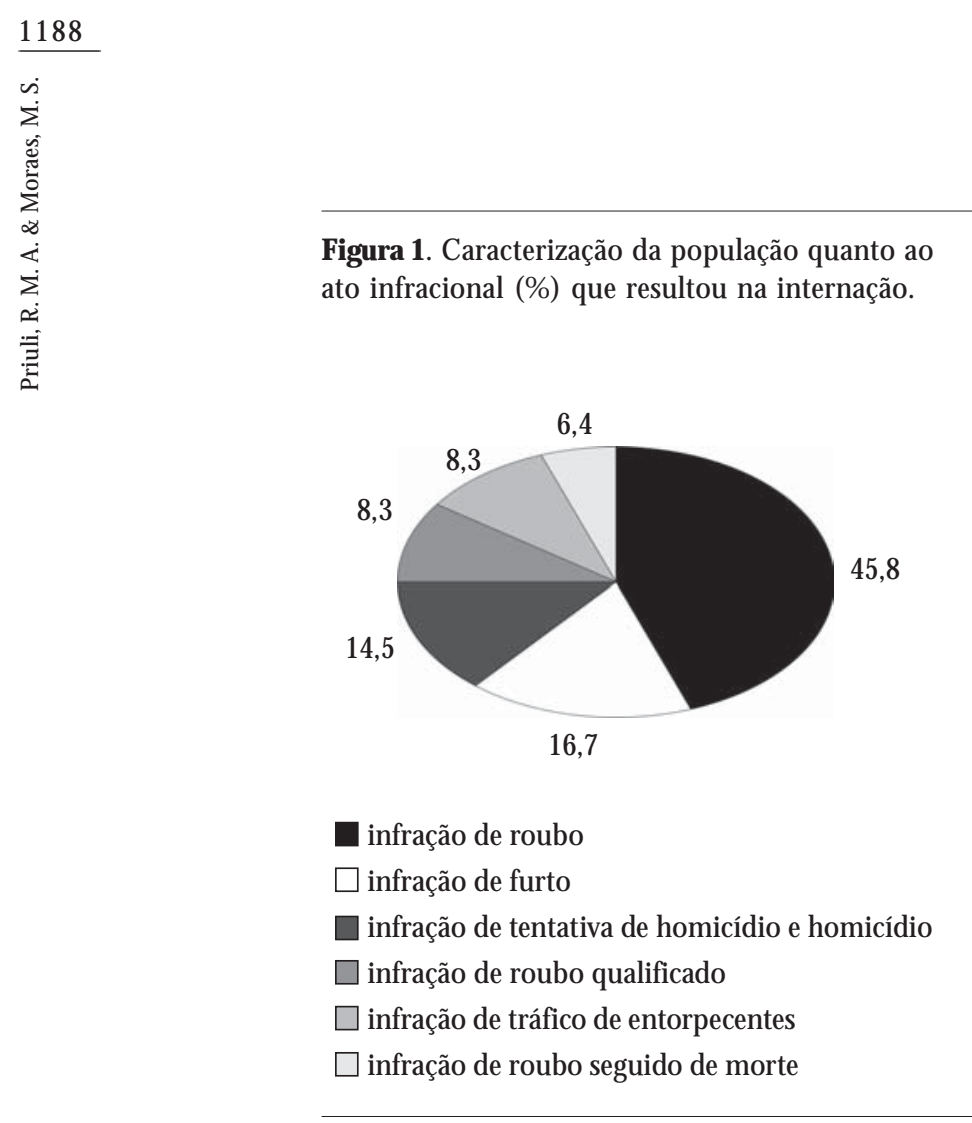

Figura 2. Caracterização dos adolescentes quanto ao uso de drogas lícitas e ilícitas segundo os tipos: tabaco, maconha, cocaína, bebida alcoólica, crack, tinner e cola de sapateiro.

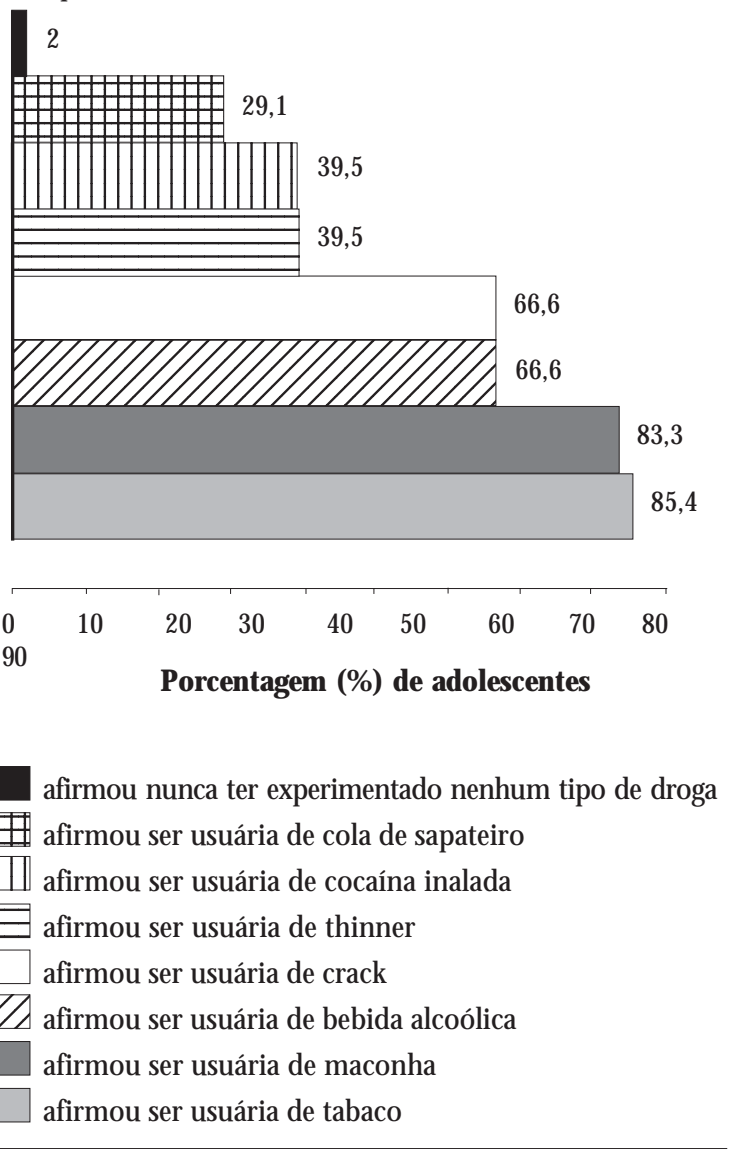

Com relação ao uso de drogas lícitas eilícitas (Figura 2), é importante assinalar que os jovens que afirmaram fazer uso do tabaco iniciaram o hábito aos 10 anos de idade ou menos (22,9\%) e os usuários de maconha, aos 12 anos ou menos $(16,6 \%)$ e aos 15 anos (16,6\%). Quanto aos jovens que disseram inalar cocaína, uma parcela de 20,8\% iniciou o hábito aos 15 anos ou menos. Constatou-se também que, para os usuários de crack, o início se deu aos 10 anos (4,1\%), atingindo a freqüência máxima de adesão aos 15 anos $(18,7 \%)$ epara aqueles queafirmaram usar o thinner o início sedeu aos 12 anos ou menos (10,4\%).

Os jovens pesquisados afirmaram que todos os amigos usavam algum tipo de droga. Além disso, entre os jovens que fizeram uso de algum tipo de droga $(97,9 \%)$ apenas uma parcela de $10,4 \%$ se submeteu ao tratamento em local especializado para drogadicção.

De acordo com os registros, levantou-se que uma grande parte dos adolescentes infratores $(77,0 \%)$ estava acompanhada de uma ou duas pessoas e $14,5 \%$ do total infracionaram sozinhos. Um dado importante é que $39,5 \%$ dos acompanhantes possuíam mais de 18 anos, sendo que $60,4 \%$ eram menores de idade. No que diz respeito ao histórico de vida infracional anterior à internação, uma parcela dos adolescentes $(37,5 \%)$ cometeu furto; $27,0 \%$ furto e roubo, totalizando, portanto, mais da metade das infrações $(56,2 \%)$ do tipo contra o patrimônio. Por outro lado, uma parcela significativa $(16,6 \%)$ não praticou qualquer infração; uma parcela de 10,4\% de jovens estava envolvida com o tráfico de entorpecentes; $8,3 \%$ outros tipos de infrações como vandalismo e porte de arma. Além disso, os dados mostram que o início da história infracional desses jovens remonta a um extenso período de vida que vai dos 7 aos 17 anos de idade. Também, a maioria dos adolescentes $(87,5 \%)$ afirmou ter sido vítima de violência policial, como ser transportado em lugar indevido no veículo da polícia, ser algemado e ser alvo de agressões verbais e humiIhações no ato da apreensão.

Um achado importantediz respeito aos locais de cometimento dos atos infracionais, que mostraram uma incidência maior na região norte de São J osédo Rio Preto (31,2\%), o quecoincidecom os locais de residência dos jovens $(70,8 \%)$.

Caracterização do grupo familiar

De acordo com a caracterização do grupo familiar, uma parte das famílias que moravam no mesmo domicílio (37,5\%) era composta por mais 
de 05 pessoas; $31,2 \%$, por até 05 e outra parte, $31,2 \%$, por até 03 pessoas. Em uma parcela significativa das famílias ( $(47,9 \%)$, os pais eram separados. Com relação à religião, houve duas tendências: 45,8\%, evangélico-protestantese $43,75 \%$, católicos.

Uma parte expressiva de pai (54,1\%) possuía o 10 grau incompleto; $20,8 \%$ não apresentavam instrução escolar; uma proporção de 10,4\% tinha o 1 o grau completo. Q uanto à mãe, os dados mostraram que uma grande parte $(72,9 \%)$ possuía 0 1 o grau incompleto, seguida de $14,5 \%$ sem instrução e de 10,4\% com o 1ํ e 2o graus completos. Com relação à profissão do pai, mais da metade $(70,7 \%)$ eram trabalhadores de serviços gerais e esporádicos; $12,5 \%$, desempregados. A respeito da profissão da mãe, os dados mostraram que a metade $(50 \%)$ trabalhava como empregada doméstica; $25,0 \%$ realizavam serviços do lar; $12,5 \%$ dedicavam-se a vendas e 6,2\% estavam desempregadas. Com referência à renda familiar, os dados evidenciaram queuma parte das famílias (41,6\%) recebia acima de um até dois salários mínimos; $31,2 \%$ até um salário mínimo; $18,7 \%$ das famílias recebiam acima de dois até três salários mínimos. Por fim, uma grande parte delas ( $77,0 \%$ ) não estava inserida em algum tipo de programa assistencial federal como bolsa criança cidadã, agente jovem, bolsa família ou benefício estadual como o programa renda cidadã.

\section{I dentificação dos familiares no período de internação}

Com relação às visitas, os dados revelam que a mãe foi a pessoa que mais visitou o adolescente $(50,0 \%)$, seguida do casal de pais $(18,7 \%)$ e depois a avó, irmã e madrasta juntamente (12.5\%); além disso, a mãe foi a figura mais citada pelos jovens $(79,1 \%)$, seguida de longe pela tia (8,3\%).

\section{Discussão}

Perfil sociodemográfico dos jovens e de seus familiares

De acordo com os dados obtidos, observouseque o maior contingente deadolescentes deSão José do Rio Preto possuía 17 anos de idade; portanto, próximo de atingir a maioridade. Estes dados estão condizentes com aqueles encontrados no grupo de adolescentes infratores do município de São Paulo e região da grande São Paulo, para um mesmo período ${ }^{16}$. Uma maior incidência de cometimento de infrações nesse período devida coincidecom o período da inimputabilidade penal, que cobre a faixa até os 18 anos incompletos, na qual prevalece a doutrina deproteção integral preconizada pelo Estatuto da Criança e do Adolescente.

Também foi detectado que a maioria dos jovens residia em bairros localizados na região norte do município, região esta, de acordo com o Boletim Epidemiológico no 2 - 2002 - Mortalidade Infantil em São José do Rio Preto, possuidora de poucos equi pamentos sociais, caracterizando-se por uma maioria populacional de menor poder aquisitivo e baixo nível de escolarida$\mathrm{de}^{20}$. Em conseqüência, esses moradores apresentam limitado acesso aos bens de consumo e às oportunidades no mercado de trabalho, se comparados aos de outras regi ões. Um outro fato que evidencia a precariedade social dessa área comparada às demais se refere ao coeficiente de mortalidadeinfantil, indicador de saúdeadotado pelo M inistério da Saúde, que se apresenta mais alto nessa região ${ }^{20}$.

Pesquisa realizada no município de São Paulo, em 1998, com 934 adolescentes autores de atos infracionais, reafirmam nossos dados, visto que mais da metade (62\%) do grupo estudado possuía o nível de 5a a 8a série do ensino fundamental, sendo que também a metade não estava freqüentando a escola21.

Quanto às condições socioeconômicas do grupo familiar, os resultados colhidos de nossas análises revelam que 47,9\% dos pais são separados, lembrando que no período da internação $31,2 \%$ dos adolescentes residiam com suas mães. Podemos supor que o provedor das necessidades da família estava primeiramente sob a responsabilidade da mãe, já que a maioria dos adolescentes não exercia atividade remuner ada. Este cenário por sua vez está embutido na estatística global do mapa da fome brasileira, em que $40 \mathrm{mi}$ Ihões de pessoas têm suas necessidades básicas negadas. Embora não se possa atribuir a estecontexto de pobreza toda prática de atos infracionais por adolescentes, é a partir destecenário que qualquer leitura e estudo sobre a violência precisa se feito ${ }^{21,22}$.

O levantamento mostrou que os adolescentes, em sua maioria, eram usuários de um ou mais tipos de drogas, a começar pelo tabaco, a maconha, a bebida alcoólica e o crack. Esses altos índices de freqüência se tornam mais preocupantes quando notamos que o início desse hábito remonta ao período da infância. Somados estes dados, obtivemos que, entre a maioria usuária, 
os amigos também faziam uso de algum tipo de substância ilícita.

Na mesma direção dos dados acima, uma investigação já apontou um grandenúmero deadolescentes brasileiros privados de liberdade, usuários de drogas $(52,0 \%)^{23}$.

Diferentemente dos dados de nossa investigação, um estudo com adolescentes, estudantes, residentes em uma cidade de médio porte no sul do Brasil detectou que a droga psicotrópica mais utilizada foi o álcool (37,8\%), seguido do tabaco $(10,3 \%)$ e da maconha (6,1\%). M ostrou também que o consumo de drogas ascendeu de forma linear com a idade, atingindo um pico no grupo dos 16 aos 17 anos, com posterior declínio na prevalência ${ }^{24}$. A ordem de preferência da maioria dos jovens estudados na nossa investigação foi diferente: tabaco, maconha e bebida alcoólica juntamente com o crack, e também detectamos um maior grau na freqüência do uso.

Achamos oportuno salientar a questão da precocidade e dos altos índices tanto no uso de drogas consideradas lícitas quanto ilícitas, pela população estudada, e a magnitude do uso do tabaco, considerando que os estudos mostram a associação al tamente significativa entre o uso de drogas ilícitas e o tabaco e entre este e 0 álcool ${ }^{24}$.

Se por um lado o imaginário social tem sido permeado pelas conexões unívocas entre pobre za e criminalidade e pelo uso de drogas, por outro lado tais relações causais não foram comprovadas, porque se tratam de associações complexas e multilineares ${ }^{7,25,26}$.

Os nossos resultados apontam para uma maior incidência de infração do tipo roubo como causadora da medida de internação que, somada à freqüência de furto, totaliza a maior parte $(62,4 \%)$ de cometimento de infração classificada pelo código penal de delito contra o patrimônio. Asinfrações queenvolvem o uso dearmas defogo totalizaram $75 \%$, o que representa uma parcela significativa dos delitos considerados, levando-nos à questão central do fácil acesso ao porte de arma ilegal por essa faixa etária da população $0^{5}$.

O bservamos também na história infracional dos adolescentes similar à situação presente do ato infracional que ocasionou a internação, uma maior proporção de furtos e furtos juntamente com roubos, sendo que uma grande parte dos adolescentes (77\%) não tinha recebido medidas outras socioeducativas como liberdade assistida, semi-liberdade, prestação de serviços à comunidade ou reparação de danos.
Papel materno no período deliberdade

Refletir sobre o papel materno no período de internação do adolescente em conflito com a lei nos remetea duas instâncias, a saber: por um lado, deve-se considerar o aqui e o agora do afastamento físico e relacional, temporário, compulsório e indeterminado, da mãe e de seu filho, numa fase crucial do desenvolvimento humano, na qual ela perdea tutela deste para o Estado. Por outro lado, étambém necessário levar-seem conta o processo de socialização desse jovem dentro de seu ambiente familiar, socioeconômico e cultural. Perder de vista o contexto histórico dessas relações primeiras é realizar um corte abrupto em nossa análise, correndo o risco de reforçarmos ainda mais o estigma do papel desta figura enquanto estereótipos do tipo "a mãe do delinqüente", "a mãe do marginal", "a mãe do infrator". Seria como uma marca que se imprimiria à questão mediante um prejulgamento de culpabilidade ou de vitimização, tanto para esta mãe quanto para seu filho, gerando um círculo vicioso e pouco frutífero às intervenções.

A medida socioeducativa de internação:

o estatuto da criança e do adolescente

versus a práxis legal

versus a práxis institucional

Os artigos 121 e 122 do Estatuto da Criança e do Adolescente-ECA, enquanto leis, determinam que a medida de internação seja uma medida de exceção, devendo ser aplicada ou mantida somente quando evidenciada sua necessidade em observância ao próprio espírito do Estatuto. É uma medida considerada grave porque restritiva de liberdade, só sendo recomendável quando desaconselhadas medidas menos gravosas, devendo ser breve excepcional. A medida de internação, por si só, não tem o propósi to de punir a conduta delitiva, mas consiste em uma forma de se criar condições adequadas para concretizar a ressocialização do adolescente.

0 advento do Estatuto não foi para ratificar uma situação de fato já consolidada na realidade cotidiana ou nas decisões dos Tribunais. Ele se impôs como matriz alterativa do imaginário ede práticas sociais, incorporando preceitos modificadores de hábitos, usos e costumes até então vigentes no trato com a criança e com o adolescente. Assim, o pensamento incorporado na lei tomou a dianteira, deixando para trás a prática se- 
dimentada, cabendo aos operadores do Direito e a todos nós acertar o passo a caminho da construção da cidadania daqueles ${ }^{27}$.

Sendo o Estatuto recente, a jurisprudência de que trata esta lei também tem que fazer jus à sua inovação; daí a necessidade do jurista adequar seu pensamento e sua prática ao ECA. Sob esta perspectiva, a gravidade do ato infracional não basta para legitimar a aplicação da internação; trata-se de uma condição necessária, mas não suficiente para tal. Tampouco bastam agregar-se à gravidade do ato infracional menções genéricas a passagens anteriores, maus antecedentes, vida ociosa, falta de respaldo familiar, como se tais circunstâncias reclamassem, de forma natural, a segregação como estratégia ressocializadora. A caracterização da excepcional idade motivadora da internação requer do magistrado um juízo mais profundo e considerações mais amplassobre múltiplosaspectos do caso, quevá além dos habituais automatismos lógico-dedutivos utilizados nas sentenças. Além disso, a situação da Febem é relevante para se considerar qual a medida mais adequada. U ma decisão judicial que aplica internação nunca será justa se, na prática, não se observarem condições adequadas para seu cumprimento. Aqui, as instituições responsáveis pela aplicação e execução da medida de internação, no Estado deSão Paulo, as Febens, são alvos de inten sas críticas em função dos seus focos prisionais mais do quesociopedagógico, estando no momento em processo de reestruturação $28,29,27,30$.
Finalmente, quanto à busca de soluções para a questão do adolescente em conflito com a lei no município deSão José do Rio Preto, podemos avaliar que são necessários construir, de forma ágil e competente junto à família, à sociedade civil, aos Poderes Executivo Municipal, Estadual e Federal, junto ao Ministério Público e Poder Judiciário, estratégias, planos de ações articuladas e complementares, convergindo todos para um foco específico: o adolescente que em um dado momento desuavida transgrediu alei e por isso é responsabilizado segundo um estatuto específico para sua idade. Estatuto este que cel ebra o adolescente sujeito de direitos e não objeto de proteção e que por essa razão demanda ações de caráter preventivo, mais eficaz e menos oneroso do que as abordagens corretivas, que caracteriza a medida socioeducativa de internação. Ainda, experiências bem sucedidas em onze Estados brasileiros comprovaram a eficácia das medidas de meio aberto como a deliberdade assistida, a de prestação de serviços à comunidade e a de semi-liberdade, todas elas com custos menores que a internação e índices mais baixos de reincidência infracional. Todas essas experiências de sucesso tiveram como marca a criatividade, o envolvimento da família, da comunidade, das autoridades e o reconhecimento de que o jovem em conflito com a lei é uma pessoa em desenvolvimento e que poderá superar a prática de infrações se lhe forem assegurados os meios adequados ${ }^{29}$. Constatamos uma realidade: ele é autor e vítima da violência.

\section{Colaboradores}

RM A Priuli e M S de Moraes participaram igualmente de todas as etapas da elaboração do artigo. 


\section{Referências}

1. Organização Mundial da Saúde(OM S). Relatório mundial sobre violência e saúde. Genebra: Organização Mundial da Saúde; 2002.

2. World Health Organization (WHO). Department of Injuries and Violence Prevention. Noncommunicable Diseases and M ental Health Cluster. The injury book: a graphical overview of the global burden of injuries Génève: World Health Organization; 2002.

3. World Health Organization (WHO). Department of Injuries and Violence Prevention. Theeconomic dimensions of interpersonal violence prevention. Génève: World Health Organization; 2004

4. World Health Organization (WHO). Injury: a leading cause of the global burden of disease. Génève: World Health Organization; 1999. [acessado 2004 Jun 7]. Disponível em: http://www.who.int/ violence injury-prevention/index.html

5. M inayo $\bar{M}$ CS. A violência na adolescência: um problema de saúde pública. Cad Saúde Pública 1990; 6(3):278-87.

6. M inayo M CS, Assis SG. Saúde e violência na infância e na adolescência. J Pediatria (Rio de J) 1994; 70(5):263-6.

7. M inayo M CS, Souza ER. É possível prevenir a violência? Reflexões a partir do campo da saúde pública. Rev C S Col 1999; 4 (1):9-15.

8. Monteiro CA. Velhos e novos males da saúde no Brasil. São Paulo: Hucitec; 2000.

9. Souza LAF. Crimes violentos: desafios para uma política de segurança pública. Psi-J Psicol CRP SP 2003; 135:8.

10. Instituto Brasileiro de Geografia e Estatística. (IBGE) Síntese dos Indicadores Sociais 2004. [acessado 2004 Jun 7]. Disponível em: http//www.ibge.gov.br.htm

11. Adorno S. Crime e violência na sociedade brasileira contemporânea. Psi- J Psicol CRP SP 2002; 132:7.

12. Jacobo JW. Mapa da violência IV: os jovens do Brasil. Unesco, Instituto Ayrton Senna, Secretaria Especial dos Direitos Humanos; 2004. [acessado 2004 Set 20]. Disponível em: http//www.unesco.org.br/publicações/ index_html

13. M ello Jorge M HP. M ortalidade por causas violentas no município de São Paulo, Brasil. Rev. Saúde Pública 1980; 14:343-57.

14. Adorno S. Precocious delinquency: young people and gangs in São Paulo (Brazil). In: Annual M eeting of Ame rican Anthropological Association, Chicago, USA. Paper. São Paulo: NEV/ USP; 1999. [acessado 2004 Fev 04]. Disponível em: http://www.nev.prp.usp.br

15. Silva APS. 0 jovem em conflito com a lei na cidade de Ribeirão Preto - SP, 1986-1996 [dissertação]. Ribeirão Preto (SP): Universidade de São Paulo; 1999.

16. Fundação Estadual do Bem-Estar do M enor (FEBEM / SP). Divisão de Tecnologia da Informação. Total deadolescentes por infração por idade por grau infracional do município de São Paulo e da grande São Paulo. 2003b. [Não Publicado].
17. Fundação Estadual do Bem-Estar do M enor (FEBEM / SP) Linha do tempo. São Paulo: 2003a. [acessado 2003 Jul 21]. Disponível em URL: http://www.febem.sp. gov.br/index/historia.htm

18. Instituto Brasileiro de Geografia e Estatística (IBGE) Censo demográfico 2000. [acessado 2004 Set 15]. Disponível em: http://www.ibge.gov.br

19. Prefeitura Municipal de São José do Rio Preto. Conjuntura Econômica de São José do Rio Preto 2001. 17ª ed. São José do Rio Preto: Prefeitura M unicipal; 2002.

20. Faculdade de M edicina de São José do Rio Preto (FAM ERP). Departamento de Epidemiologia e Saúde Coletiva. M ortalidade infantil em São José do Rio Preto, SP. Boletim Epidem 2002; 2.

21. M inayo MCS, Souza ER. Violência e saúde como um campo interdisciplinar e de ação coletiva. Rev C S Col 1998; 4(3):513-31.

22. Volpi M. O adolescente e 0 ato infracional. INALUD 2001; 14:21-32.

23. Volpi $M$, organizador. 0 adolescente e 0 ato infracional 4a ed. São Paulo: Cortez; 2002.

24. Deitos FT, Santos RP, Pasqual otto AC, Segat FM, GuiIlande $S$, Benvegnú L. Prevalência do consumo de tabaco, ál cool e drogas ilícitas em estudantes de uma cidade demédio porteno sul do Brasil. Inf Psiquiatr 1998; 17(1):11-6.

25. Souza ER, Ximenes LF, Alves F, M agalhães $C$, Bilate $D$, Szuchmacher AM et al. Avanços do conhecimento sobre causas externas no Brasil e no mundo: enfoque quantitativo e qualitativo. In: M inayo M CS, Souza ER. Violência sob o olhar da saúde: a infrapolítica da contemporaneidade brasileira. Rio de Janeiro: Editora Fiocruz; 2003. p. 131-60.

26. Chesnais JC. A violência no Brasil. Causas e recomendações políticas para a sua prevenção. Rev C S Col 1999; 4(1):54-65.

27. Frasseto FA. Ato infracional, medida sócio-educativa e processo: na nova jurisprudência do Supremo Tribunal de Justiça. Rev Bras Ciênc Criminais 2001; 9(33):177-201.

28. Garcia M endes E. Partel. In: Garcia M endes E; Gomes da Costa AC. Das necessidades aos direitos. São Paulo: Malheiro; 1994.

29. Spozato K. O jovem: conflitos com a lei. A lei: conflitos com a prática. Rev Bras Ciênc Criminais 2000; 8(30):108-14.

30. GomideP. M enor infrator: a caminho de um novo tempo. 2a ed. Curitiba: Juruá; 2003.

Artigo apresentado em 03/01/2005

Aprovado em 25/09/2005

Versão final apresentada em 23/02/2006 